\title{
CORRIGENDUM
}

\section{Anxiety prevalence following spinal cord injury: a meta-analysis}

\author{
J Le and D Dorstyn
}

Spinal Cord (2016) 54, 626; doi:10.1038/sc.2016.69

Correction to: Spinal Cord (2016) 54, 570-578; published online 8 March 2016

Since the publication of this article, the authors have noticed missing information in Appendix B: Data extraction sheet. The corrected appendix can be found below.

\section{APPENDIX B}

Data extraction sheet

\begin{tabular}{|c|c|c|}
\hline \multicolumn{3}{|l|}{$\begin{array}{l}\text { Article Title: } \\
\text { Author: } \\
\text { Year: } \\
\text { Country: }\end{array}$} \\
\hline \multicolumn{3}{|l|}{ Sample characteristics } \\
\hline $\begin{array}{l}\text { Age at assessment }(>18 \text { years) } \\
\square \text { Estimated by available data (mean } \\
\text { age minus } 1 \mathrm{SD} \geq 18 \text { years) } \\
\square \text { Specified overall } \\
\text { Mean (SD): } \\
\text { Median: } \\
\text { Range : } \\
\square \text { Specified via sub-groups (so can } \\
\text { calculate overall) } \\
\text { Sample size } \\
\text { SCI group (N = ) } \\
\text { Comparison group (N= ) } \\
\text { Specify comparison group (healthy vs } \\
\text { other disability): }\end{array}$ & 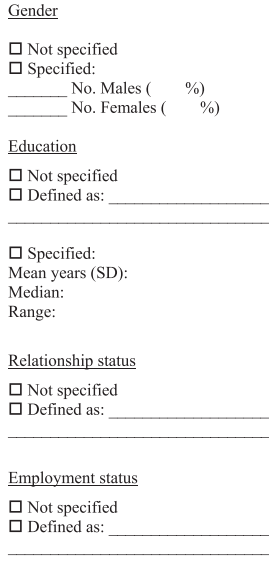 & 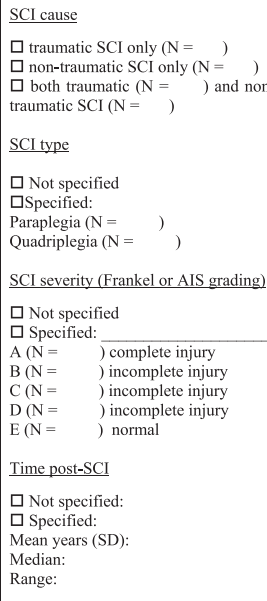 \\
\hline \multicolumn{3}{|l|}{ Effect size data } \\
\hline \multicolumn{3}{|c|}{$\begin{array}{l}\text { Outcome measure: } \\
\text { Method of administration: } \square \text { self-administration } \square \text { clinical interview } \square \text { other: } \\
\text { Cut-off score (if applicable): } \\
\text { Prevalence estimate: }\end{array}$} \\
\hline
\end{tabular}

The PDF and online versions have also been amended. The authors apologise for any inconvenience caused. 